\title{
Possibilities of using hydrolytic lignin in the production of wood-splicing materials
}

\author{
Nikolay Plotnikov ${ }^{1, *}$, Galina Plotnikova ${ }^{1}$, and Natalia Vaynshtok ${ }^{2}$ \\ ${ }^{1}$ Bratsk State University, 665709, Makarenko Street 40, city of Bratsk, Irkutsk region, Russia \\ ${ }^{2}$ Moscow State University of Civil Engineering, Yaroslavskoe shosse, 26, Moscow, 129337, Russia
}

\begin{abstract}
The problem of improving the environmental safety of the waste management system of chemical processing of biomass of wood is quite acute in every forest producing and timber processing region. Study of the possibility of using to investigate hydrolytic lignin as a modifier of phenol-formaldehyde resin for the production of plywood have been conducted. Used materials: phenol-formaldehyde resin SFZh-3013; technical hydrolyzed lignin. Mathematical models of the process of pressing glued plywood were developed and the optimal parameters for the production of plywood were determined based on the use of SFZh-3013 resin modified with hydrolytic lignin. The optimal mode of pressing is: the amount of injected hydrolytic lignin in the SFZh-3013 resin grade is 5-10 parts by weight; pressing pressure $1.6 \mathrm{MPa}$, pressing temperature $135^{\circ} \mathrm{C}$ and pressing time 9-10 minutes. The introduction of regimes developed using regression equations, with a sufficient degree of accuracy describing the pressing process, will significantly improve the efficiency of plywood production by saving energy and material costs and preserving product quality.
\end{abstract}

\section{Introduction}

One of the directions of processing plant materials is the use of acid hydrolysis of woody biomass, which historically has been directed to the use of the carbohydrate part, to produce ethanol. During the hydrolysis of wood waste is formed - technical hydrolytic lignin (THL). To date, the enterprises have accumulated many millions of tons of hydrolytic lignin [1-6]. Lignin, along with cellulose and protein substances, is one of the most common natural polymers, which in itself determines the significance of research aimed at understanding its nature and behavior in chemical reactions. Currently in the woodworking industry, liquid hot-cured resole resins are used. However, the high cost and scarcity of phenol significantly increases the cost of products based on these resins - the proportion of binder in the cost of laminated wood is up to $40 \%$. Thus, the use of technical lignins for the production of low molecular weight phenolic compounds will reduce the cost of production products using phenol, such as, for example, the production of binding resins for the production of plywood, fiberboard [7-10]. The aim of the work is the development of technological

* Corresponding author: n-plotnikov@mail.ru 
modes of production of glued plywood with improved physico-mechanical parameters based on the use of phenol-formaldehyde resins modified with lignin hydrolyzed.

\section{Materials and methods}

The work was carried out on peeled veneer samples made of pine wood on a fiberboard. Studies to determine the physicochemical parameters of modified resins were carried out in accordance with GOST 20907 "Phenol-formaldehyde resins". Studies to determine the wetting ability of modified resins were performed using an MIS-11 microscope. The gluing of plywood with the format of $0.4 \mathrm{mx} 0.4 \mathrm{~m}$ was carried out in a laboratory press of the brand OKS $1671 \mathrm{M}$ according to the following technological parameters: humidity of pine veneer - $6 \pm 2 \%$; glue consumption - $120 \mathrm{~g} / \mathrm{m} 2$; plywood thickness - $12 \mathrm{~mm}$; layer pack 5; package assembly and holding time before gluing - $10 \mathrm{~min}$; gluing in one gap of the press 1 sheet each; aging after gluing - no less than 24 hours. The physicomechanical parameters of the finished product were determined according to GOST 3916.2-96 "General-purpose plywood with outer layers of softwood veneer" [11-14]. The obtained experimental data of one-and multi-factor experiments were processed by the methods of mathematical statistics.

Used materials:

- phenol-formaldehyde resin SFZh-3013;

- technical hydrolyzed lignin.

According to the statements of numerous authors [Doronin Yu. G., Kodratyev V.P., Anokhin A.E., Bokov A.N. et al.] adhesion of adhesive joints largely depends on the processes of wetting and spreading of the adhesive, the evaluation of which is the wetting ability of the surfaces of the glued veneer [15-18]. Therefore, at the first stage of the research, the determination of wetting ability was assumed, the criterion of which is the wetting angle. The measurement of the wetting angle of the modified adhesive compositions was carried out on samples of peeled veneer made from pine wood, as well as on a substrate of hardboard using a microscope MIS-11 [19-22].

\section{Results}

The results of studies of the dependence of the wetting angle on a peeled veneer substrate and a fibreboard substrate on the amount of hydrolyzed lignin added to a SFG-3013 phenolformaldehyde resin are presented in the form of graphical dependencies in Fig. 1.

From the presented graphical dependence, we can draw the following conclusion that the wetting ability of the pine veneer substrate is worse than fiberboard. With an increase in the input of hydrolytic lignin, the wetting angle increases, therefore, the wetting ability deteriorates. Surface tension is directly related to the work of adhesion. Interfacial interaction, or interaction between the surfaces of condensed bodies brought into contact of different natures, is called adhesion (adhesion). The work of adhesion Wa, characterizing the strength of the adhesive bond, is determined through the cosine of the wetting angle and surface tension. According to the data obtained, the dependence of the work of adhesion on the amount of hydrolyzed lignin in the adhesive composition, shown in Fig. 2.

From the presented graphical dependence we can draw the following conclusion: with an increase in the amount of hydrolyzed lignin introduced into the composition, the work of adhesion increases. Adding 5-10 parts by weight of hydrolytic lignin does not significantly increase adhesion. With further increase in the number of injected hydrolytic lignin, the work of adhesion increases dramatically. Using the obtained results of preliminary experiments, in laboratory conditions at the Department of Reproduction and processing of forest resources of the Bratsk State University, studies on gluing veneer were carried out 
and studying the strength properties of the materials obtained. The variable factors of research and the intervals of their variation are given in table 1.

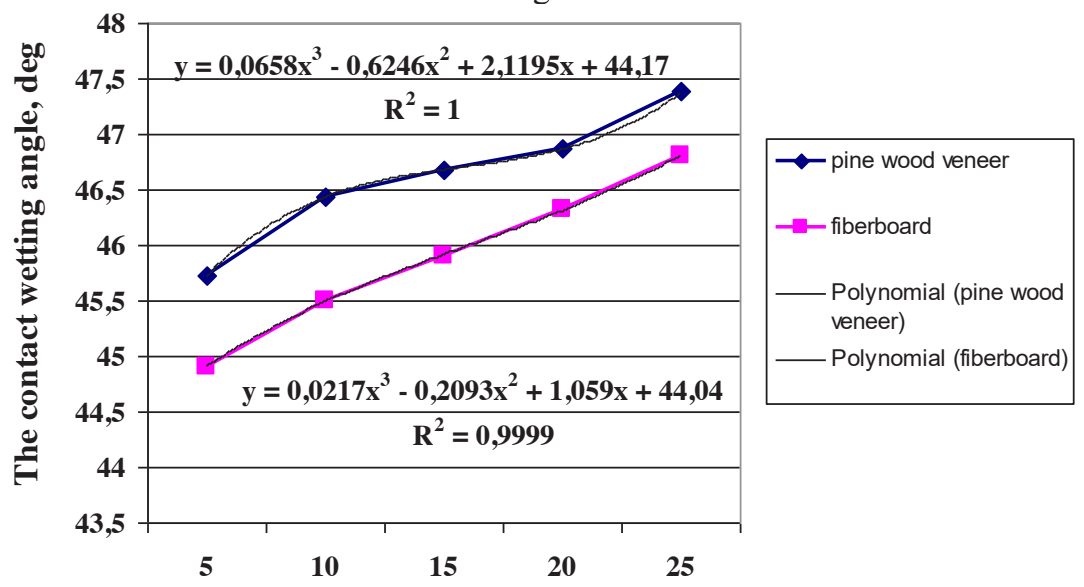

The content of hydrolytic lignin,

wt.h.

Fig. 1. Schedule of dependence of the average values of the wetting angle.

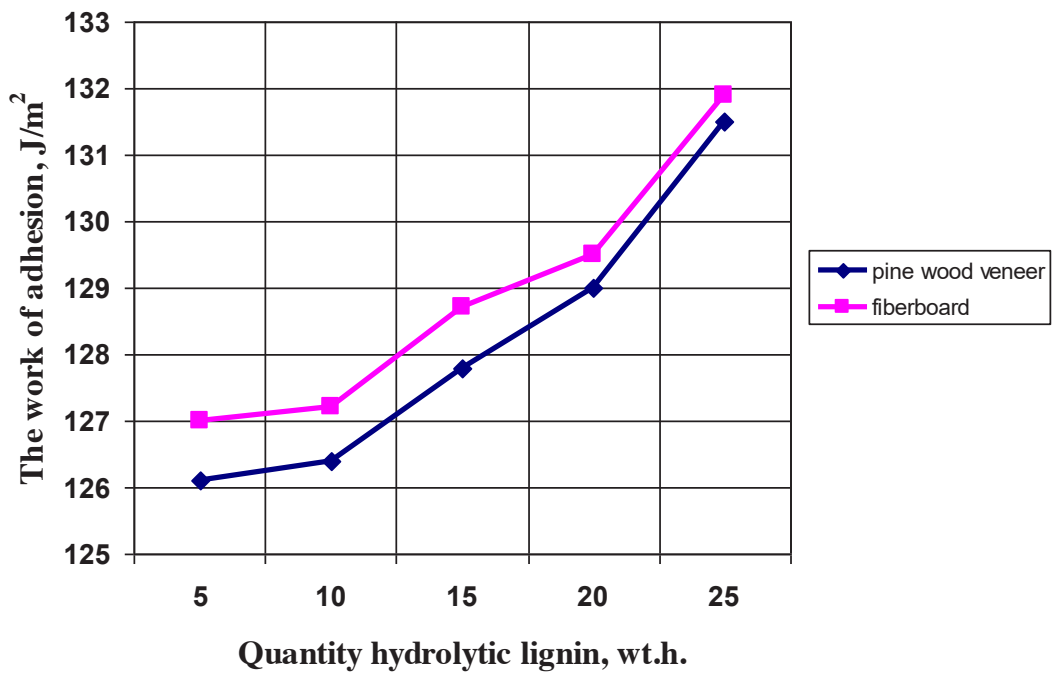

Fig. 2. Schedule of adhesion versus input quantity hydrolytic lignin in the adhesive composition.

Table 1. Main factors and levels of their variation.

\begin{tabular}{|c|c|c|c|c|c|}
\hline Name of the factor & Designation & $\begin{array}{c}\text { Lower } \\
\text { level }\end{array}$ & $\begin{array}{l}\text { Basic } \\
\text { level }\end{array}$ & $\begin{array}{c}\text { Upper } \\
\text { level }\end{array}$ & $\begin{array}{c}\text { Variation } \\
\text { interval }\end{array}$ \\
\hline Amount of hydrolytic lingin, wt.h. & $X_{1}$ & 5 & 10 & 15 & 5 \\
\hline Pressing pressure, $P, \mathrm{MPa}$ & $X_{\text {L }}$ & 1.4 & 1.6 & 1.8 & 0.2 \\
\hline Pressing cycle duration, $\tau_{1}$, min & $X_{\square}$ & 9 & 10 & 11 & 1 \\
\hline Pressing temperature, $t,{ }^{\circ} \mathrm{C}$ & $X_{4}$ & 115 & 125 & 135 & 10 \\
\hline
\end{tabular}

Mathematical description of the dependence of the tensile strength of plywood for bending: 


$$
Y_{1}=42,63-0,97 \cdot X_{1}+1,73 \cdot X_{1}-6,33 \cdot X_{2}^{2}+6,03 \cdot X_{4}^{2}+0,375 \cdot X_{1} \cdot X_{2}
$$

Mathematical description of the dependence of the strength of glued plywood on chipping on the adhesive layer:

- in dry form:

$$
Y_{2}=2,02-0,102 \cdot X_{1}+0,036 \cdot X_{4}+0,21 \cdot X_{1} \cdot X_{4}-0,09 \cdot X_{2}^{2}
$$

- after boiling

$$
\begin{array}{r}
Y_{a}=1,265-0,064 \cdot X_{1}-0,261 \cdot X_{4}-0,012 \cdot X_{1} \cdot X_{4}+ \\
+0,15 \cdot X_{2}^{2}-0,3 \cdot X_{1}^{2}+0,115 \cdot X_{1}^{2}+0,15 \cdot X_{4}^{2}
\end{array}
$$

At the next stage, a multifactorial experiment was conducted in order to obtain an adequate mathematical description of the technological production of plywood.

Based on the obtained research results, mathematical models were developed for describing the research process, which allow predicting the strength characteristics of the plywood produced with a given probability. According to the obtained regression equations, graphical dependences in the form of response surfaces are constructed. The dependence of the strength of plywood when it is spalled over the adhesive layer after boiling for 1 hour is shown in Fig. 3.

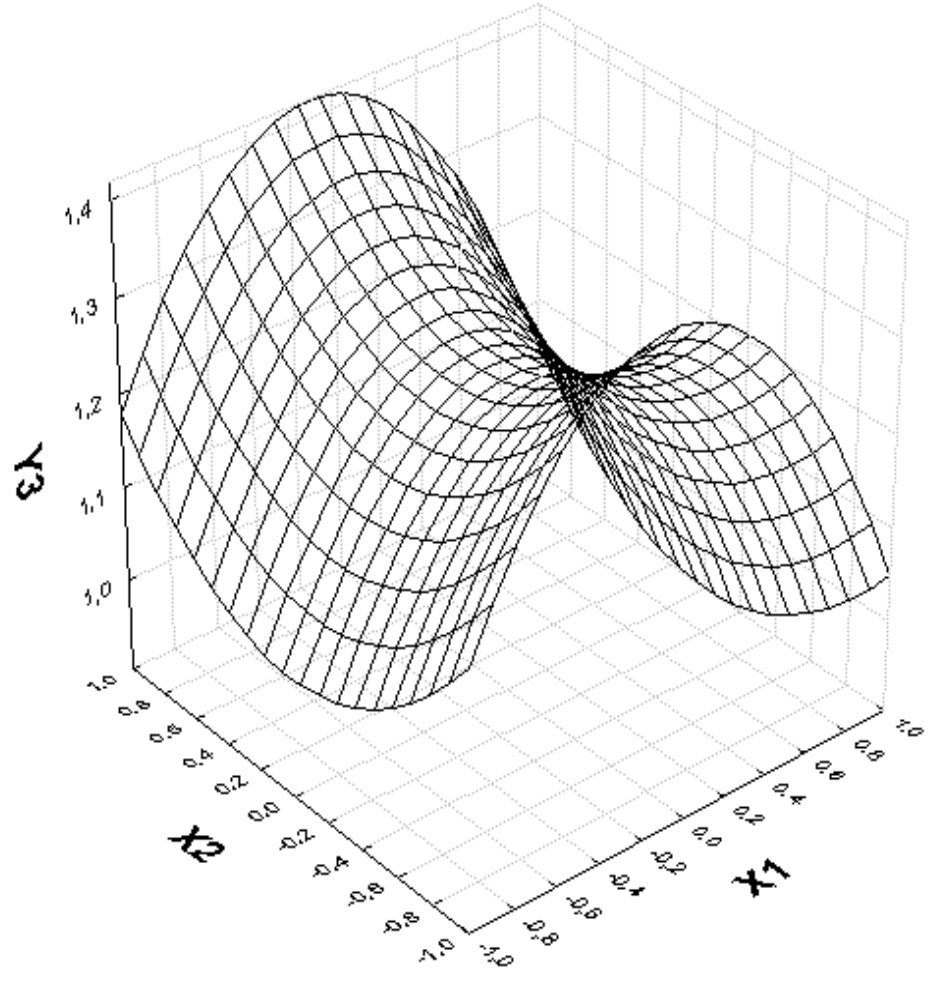

Fig. 3. Dependence of the strength of plywood when it is spalled over the adhesive layer after boiling for 1 hour. 


\section{Discussion}

From the presented graphical dependence, we can conclude that the maximum strength of plywood samples on the basis of SFZh-3013 modified with hydrolytic lignin on the adhesive layer after boiling for 1 hour is observed during the pressing cycle of 10 minutes, pressing temperature $135^{\circ} \mathrm{C}$, pressing pressure $1.6 \mathrm{MPa}$, when the content of hydrolytic lignin 10 wt.h.

From the presented graphical dependence, it can be concluded that the maximum maximum tensile strength of plywood samples based on SFG-3013 modified with hydrolytic lignin during static bending is observed at a pressing temperature of $135{ }^{\circ} \mathrm{C}$, a pressing cycle of 10 minutes, a pressing pressure of $1.8 \mathrm{MPa}$, and a content of hydrolytic lignin 5-10 wt.h.

\section{Conclusions}

1. Thus, after analyzing the schedules of the effects of factors and their interactions, it can be concluded that the optimal mode of pressing is: the amount of injected hydrolytic lignin in the SFZh-3013 resin grade is 5-10 parts by weight; pressing pressure 1.6 MPa, pressing temperature $135^{\circ} \mathrm{C}$ and pressing time $9-10$ minutes.

2. The introduction of regimes developed using regression equations, with a sufficient degree of accuracy describing the pressing process, will significantly improve the efficiency of plywood production by saving energy and material costs and preserving product quality.

\section{References}

1. R.R. Safin, R.R. Khasanshin, A.R. Shaikhutdinova, A.V. Safina, Research of heating rate while thermo modofication of wood,. World Applied Sciences Journal 30 (11), 1618-1621 (2014)

2. D.V. Tuntsev, R.R. Safin, R.G. Hismatov, R.A. Halitov, V.I. Petrov, The mathematical model of fast pyrolysis of wood waste. Proceedings of 2015 International Conference on Mechanical Engineering, Automation and Control Systems, MEACS, 741-749 (2015)

3. N.R. Galyavetdinov, R.R. Safin, A.E. Voronin, Analysis of physico-mechanical properties of composites based on polylactide abd thermally modified wood fibers, Materials Science Forum 870, 202-206 (2016)

4. D.S. Rusakov, G.S. Varankina, A.N. Chubinskii, Modification of phenol-and carbamideformaldehyde resins by cellulose by-products, Polymer Science, Series D 1 (11), 1, 33-38 (2018)

5. S.A. Ugryumov, A method of quantitative evaluation of the content of free furfural in glued wood materials based on furan oligomers, Polymer Science, Series D 1(6), 5153 (2013)

6. S.A. Ugryumov, G.S. Varankina, A.N. Chubinskii, V.A. Katsadze, A modified glie for producing particle boards and boards based on waste of annual plants, Polymer Science, Series D 12 (3), 251-253 (2019)

7. S. Barcík, S. Ugryumov, E. Razumov, R. Safin, Studies of component interconnection in a plywood structure with internal layers of veneer chips, Acta Facultatis Xylologiae Zvolen 61 (1), 121-129 (2019) 
8. S.A. Ugryumov, R.V. Patrakov, The use furan oligomers for modifying phenolformaldehyde resin in plywood industry, Polymer Science, Series D 4 (1), 38-40 (2011)

9. S.P.J.M. Carrot,. M.M.L.R. Carrot,. Lignin - from natural adsorbent to activated carbon: a review, Bioresource Technology 98, 2301-2312 (2007)

10. R.R. Safin, F.V. Nazipova, R.R. Khasanshin, A.E. Voronin, Pre-treatment of vegetable waste in the production of composite materials, Key Engineering Materials 743, 53-57 (2017)

11. R.R. Safin, F.V. Nazipova, R.R. Ziatdinov, et.al. The effect of ultrasonic extraction of soluble sugars from the wood filler on the strength properties of the composite based on mineral binder, Key Engineering Materials 688, 138-144 (2016)

12. R.R. Safin, A.F. Zamilova, M.F. Galikhanov, R.R. Ziatdinov, A.F. Garaeva, Intensive technology of creation of the high-strength and moisture resistant plywood materials. International Multidisciplinary Scientific GeoConference Surveying Geology and Mining Ecology Management, SGEM 17, Nano, Bio and Green - Technologies for a Sustainable Future 231-238 (2017)

13. R.R. Safin, G.F. Ilalova, R.R. Khasanshin, Study of pyrolysis of annual crop refuse under reduced pressure. Solid State Phenomena 299, 974-979 (2020)

14. R.R. Safin, N.R. Galyavetdinov, Sh.R. Mukhametzyanov, A.R. Shaikhutdinova, R.R. Khasanshin, Technology for producing high-qualoty natural biodegradable plastic fpr $3 d$ printer. 19th International scientific geoconferense SGEM 2019 Conference proceedings, Sofia, 503-510 (2019)

15. R.R. Khasanshin, R.R. Safin, et.al. Effect of process pressure on the yield of products and the duration of the process of thermochemical processing of wood waste. 19th International scientific geoconferense SGEM 2019 Conference proceedings, Sofia, 145-152 (2019).

16. G.P. Plotnikova, N.P. Plotnikov, E.A. Kuzminih, The use of hydrolytic lignin in the production of wood-polymer composites, System. Methods. Technology 4, 133-138 (2013)

17. N.P. Plotnikov, G.P. Plotnikova, S.H. Simonyan, Modeling of technological process of wood composite material production of woodworking and wood chemical complex wastes, International Journal of Applied Engineering Research 10 (6), 15131-15139 (2015)

18. N.P. Plotnikov, G.P. Plotnikova, Application of lignin in production wood-polymer composites, E3S Web of Conferences. Topical Problems of Green Architecture, Civil and Environmental Engineering, TPACEE 2019. P. 14011 (2020)

19. N.P. Plotnikov, G.P. Plotnikova, Structure of naphtol modified urea-formaldehyde resins by using the method of nuclear magnetic resonance, Research Journal of Pharmaceutical, Biological and Chemical Sciences. 5(6), 1466-1472 (2014)

20. N.P. Plotnikov, G.P. Plotnikova, Improvinent of the production technology of woodbased materials, NP «SibAC» 112 (2013)

21. G.P. Plotnikova, N.P. Plotnikov, Optimization of the production process of chipboard on a modified binder with the use of substandard raw materials, Bulletin KrasSAU 9, 249-256 (2013)

22. G.P. Plotnikova, N.P. Plotnikov, Modification of the binder for the use of substandard raw materials in the production of chipboard, Systems. Methods. Technology 2, 142146 (2013) 